\title{
Prevalence of HIV/AIDS Among Pregnant Mothers Aged 18 - 49 Years Attending Antenatal Clinic At Mukono Health Centre IV.
}

\author{
Ramadhan Ndhego ${ }^{a}$ \\ a Health Tutors' College Mulago Makerere University
}

\begin{abstract}
\end{abstract}

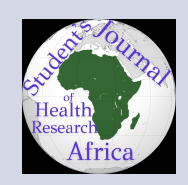

Introduction: ${ }^{a}$

The HIV/AIDS epidemic is a serious threat to social and economic development around the world. Uganda's HIV/AIDS prevalence rate has shot up from $6.4 \%$ in 2005 to $7.3 \%$ whereas in pregnant mothers of all ages is at $6.1 \%$. The prevalence of HIVIAIDS in Mukono district in Uganda worries leaders, and according to the local newspaper, the general prevalence in this area is said to be $9 \%$. No study has documented the prevalence among pregnant women attending antenatal care at Mukono Health centre IV.

Methods:

The study took place at Mukono HCIV which is found in Mukono municipal council Mukono district on Kampala - Jinja road. The design was cross-sectional using both quantitative and qualitative methods where the pregnant mothers between the ages 18-49yrs were involved in the study at the antenatal clinic using the methods that are provided for their inclusion and exclusion study purposes. The data was summarized in form of bar graphs, pie charts, and tables using Microsoft excel program and SPSS.

Results:

The general prevalence of HIV/AIDS among pregnant women who sought ANC in Mukono Health Centre IV was $7 \%$. The research indicated that the majority of the pregnant women $n=88$, were in the age group of 25-31 years $49(55.7 \%)$, $31(35.2 \%)$ had attained a secondary level of education while 30(34.1\%) had attained a tertiary level of education.

\section{Conclusion and recommendation:}

Positive mothers should get access to psychological support hence enhancing the utilization of VCT by the mothers. Men's involvement is necessary, and they need to be encouraged and sensitized from the communities to accompany their partners to the clinic and attend counseling sessions, this is to help equip them both with the necessary information on PMTCT.

\footnotetext{
${ }^{a}$ Journal of Obstetrics and Gynecology. email:ndhegoramadhan@yahoo.com Received: $1^{\text {st }} / 03 / 2021$ Accepted: $2^{\text {nd }} / 03 / 2021$
}

\section{Background of the study}

The background of the study is about the prevalence of HIV/AIDS in pregnant mothers. HIV is a lentivirus (a member of the retrovirus family) that causes AIDS (Jawetz et al., 2007). It causes AIDS where the immune system begins to fail, leading to life-threatening opportunistic infections. It attacks CD4 helper lymphocytes which are the first line 
of defense; it then proceeds to invade monocytes, macrophages leading to progressively weakening the body's immune system resulting in immune deficiency. Following infection, a virus takes over the synthesizing activities of its host cell, directing the cell to transcribe and, or, translate its genetic information to produce the protein and nucleic acid components required to make new virions (Cheesbrough, 2005).

Two types of HIV have been recognized, HIV1 and HIV- 2. HIV-1 is more virulent and more widely spread than HIV 2 which is mostly found in West Africa (Yesufu et al., 2011). The first cases of HIV/AIDS were identified by doctors in San Francisco and New York, while in Uganda were identified in 1982 in Rakai district. Studies show that HIV/AIDS killed more than 25 million people between 1981 when it was first recognized, and 2005, making it one of the most destructive pandemic in recorded history (UNAIDS \& WHO, 2005).

Despite improved access to antiretroviral treatment and care in many regions of the world, the AIDS pandemic claimed an estimated 2.8 million (between 2.4 and 3.3 million) lives in 2005 of which more than half a million $(570,000)$ were children (CDC, 2006).

According to statistics of the global HIV and AIDS published by UNAIDS in NOV/2009, 15.7million women were living with HIV/AIDS in 2008. SubSaharan Africa statistics for HIV and AIDS by the end of 2008 was 22.4 million adults and children living with HIV/AIDS, 1.9 million adults and children newly infected, the adult prevalence aged (1849)years was $5.2 \%$, and 1.4 million deaths of adults and children. 2 million deaths were registered in this very year despite improvements in access to antiretroviral treatment.

In rural South Africa population-based HIV, prevalence estimates for all women are rated at $25.2 \%$ and pregnant women $23.7 \%$ significantly lower than that for ANC attendees (37.7\%) (Rice et al., 2007).

HIV/AIDS is not strictly a disease of poverty as it affects people at all income levels. But evidence from some countries at advanced states of epidemic shows that new HIV infections disproportionately affect poor people, unskilled workers, and those lacking literacy skills especially young women in each of these categories (Bjorkman, 2002).

Uganda's women and so Mukono are vulnerable to HIV given their low status, lower education attainment, higher unemployment, and weaker negotiating skills in relationships (Kiddugavu et al., 2003).

According to Uganda's poverty reduction strategy paper, at the level of the household, poverty is related to rural residence, land shortage, low levels of education, being headed by a female widow or by someone old, unequal sharing of resources within the household reflects not only cultural factors but unequal access to education and physical assets like land in which women are disadvantaged (IMF, 2000).

The HIV/AIDS epidemic is a serious threat to social and economic development around the world. In Uganda, the prevalence rate has increased from $7.5 \%$ to $8.3 \%$ among women compared to $6.1 \%$ among men and that in pregnant mothers of all ages is $6.1 \%$ (UNAIDS, 2014). The prevalence of HIVIAIDS in Mukono worries leaders as the general prevalence in this area is $9 \%$ (New Vision,6th/Feb/2014). According to the DHO, Mukono, Dr. Elly Tumushabe this high prevalence is thought to be due to the place being urban, made of islands, landing sites, poor participation for the males in HIV testing, lack of women empowerment, revenge tendencies, poverty, malice, multiple partners, religious beliefs where the use of condoms may be prohibited. These and many others can lead to high exposure rates of HIV /AIDS to the highly vulnerable mothers and so reduction in the economic stand and so morbidity and mortality as this is well reflected in the report where the HIV/AIDS -infected pregnant or post-partum women have around eight times higher mortality than their HIVuninfected counterparts. Based on this estimate, it is predicted that roughly $24 \%$ of deaths in pregnant or post-partum women are attributable to HIV in sub-Saharan Africa (ALPHA, 2008). Their measures were put in place to curb down the disease like the use of the $A B C$ approach and others but the disease is still just advancing. Therefore the major aim of this research was to establish the prevalence of HIV/AIDS in pregnant mothers at the antenatal Clinic at Mukono HC IV.

\section{METHODOLOGY}

\section{Study area}

The study took place at Mukono HCIV which is found in Mukono municipal council Mukono district on Kampala - Jinja road. This is generally in the 
Buganda region part of Uganda and its catchment areas include Wantoni, Dandila, Nakabago, Namuyenje, Mukono, Bugujju, Nabuti, Kitega, Mpoma , Nantabulirirwa, Sombe , Nasuti ,Seeta, Kigombya , Kigunga, Lutengo , Kilowoza, Kyetume, Namataba , Kasangalabi , Kawuga and many other places.

The health center has a functional outpatient department, inpatient department, laboratory, antenatal clinic and it offers the following services; VCT, PMTCT, RCT, minor and major operations on addition, it conducts outreaches, and VCT programs to enable me to understand the prevalence and the factors leading to the spread of HIVIAIDS in mothers this area.

\section{Study population}

The study population was the pregnant mothers between 18 and 49 years attending Antenatal Clinic Mukono HCIV.

\section{Study design}

The design was cross-sectional using both quantitative and qualitative methods where the pregnant mothers between the ages 18-49 shall be involved in the study at the antenatal clinic using the methods that are provided for their inclusion and exclusion study purposes.

\section{Study variables}

The dependent variables were the pregnant mothers, age, abstinence, and type of family

The independent variables included; factors leading to the spread of HIV/AIDS in pregnant mothers attending ANC at Mukono HCIV and Sero-status.

\section{Sample size determination}

The sample size was determined using the formula of Kish and Leslie.

$$
\begin{aligned}
& \mathrm{N}=\mathrm{Za}^{2} \mathrm{pq} \\
& \mathrm{d}^{2}
\end{aligned}
$$

\section{$\mathbf{N}=$ Sample size}

Za Standard deviation at confidence level of $95 \%$ $=1.96$

$$
\begin{aligned}
& P=\text { Prevalence }=6.1 \% \\
& Q=1-P \\
& d=\text { standard error }=0.05 \text { or } 5 \% \\
& N=1.96^{2} \times 0.061 \times 1-0.061 / 0.05 \times 0.05 \\
& N(\text { Sample size })=88
\end{aligned}
$$

\section{Sampling procedure}

The method of sampling used was simple randomisation whereby numbered lists of all the units (Respondents) in the population were made from which the researcher drew the sample. Each unit on the list was numbered in sequence from 1 to $\mathrm{N}$ (where $\mathrm{N}$ is the size of the population) and the sample size was decided and selected from the same using "lottery" whereby each unit in the population was represented by a slip of paper and these were put in a box and mixed, and a sample required was drawn from the box. Eleven respondents daily for eight working days where interviewed to complete data collection for all the 88 respondents.

\section{Inclusion and exclusion criteria}

All pregnant mothers between the ages of 1849 who had been counseled and obtained an informed written consent were included in the study. The mothers, who were not counseled, never obtained informed and no written consent was excluded from the study. The mothers' particulars like name, age, treatment obtained, and the number of times one has been tested shall be kept confidential.

\section{Study instrument}

A well-developed questionnaire was administered to the pregnant mothers of age 18-49years attending ANC Mukono Health Centre IV.

\section{Reliability and validity of the research instru- ments}

To ensure accurate results, items in the instruments were adequately and appropriately organized according to the objectives of the study. The data collection instruments were further discussed with the research supervisor to ensure accuracy and appropriateness.

For consistent and reliable results from the research instrument used, the researcher ensured that the instruments used were constructed using simple language and appropriate vocabulary for the selected respondents.

Before administration of the tool, the tool was pre-tested using mothers from other health Centres, and thereafter, the tool was edited to fill in all missing information.

\section{Data collection procedure}

One data research assistant from within the Health Centre was orientated about the study mainly on the data collection tool and on how to collect data from the records. Data collection took eight working days and eleven respondents were interviewed per day. The research assistant was under my supervision in interviewing the clients.

\section{Data Management}

The computer package that was used was SPSS computer application software version 14.0. 
The Data Cleaning was done by erasing unnecessary information and the use of only one typist who worked as a data entry clerk.

The coding of data was done followed by proofreading to check for normality and transformation.

\section{Data analysis}

The data collection tool used was a questionnaire and other information was obtained from the records and analysis was done with the help of a statistician, and the data was summarized in form of bar graphs, pie charts, and tables using Microsoft excel program and SPSS computer application software version 14.0.

\section{Ethical consideration}

The proposal was presented to the research committee of Health Tutors' College for approval.

Permission to carry out the study was sought from the in the charge of Mukono Health Centre IV and also every mother who was recruited in the study consented.

\section{Limitation of the study}

- The busy schedule of respondents disrupting the data collection process

- Climate changes especially rain ${ }^{1}$

- Insufficient funding

\section{ANALYSIS AND}

\section{PRESENTATION OF RESULTS}

Source: Data collected from Mukono Health Centre IV for this research project

From Table 1, out of the 88 pregnant women who completed the questionnaire, 49 (55.7\%) were in the age group of 25-31 years, closely followed by those in the age group of $15-24$ years $26(29.5 \%)$ 79(89.8\%) were married,5.0(5.7 \%) were widowed and 04 (4.5\%) were single.

As regards the education level, 31(35.2\%) had attained secondary education while 30(34.1\%) had attained tertiary education, 25(28.4\%) had attained primary and 2(2.3\%) had never acquired formal education.

Of all the pregnant women who came to the health facility for antenatal care, $69(78.4 \%$ of them were Baganda followed by Basoga 6(6.8\%).
$43(48.9 \%)$ of all the pregnant women who attended Mukono Health Centre IV were Catholics, followed by Anglicans who were 30(34.1\%).

The social-economic status of the people stands as $39(44.3 \%)$ employed as a way of livelihood while $51(55.7 \%)$ were jobless.

The results also showed that very many people are aware that HIV/AIDS is still a problem $87 / 88(98.9 \%)$ indicating that only $2(0.1 \%)$ say HIV/AIDS is no longer a problem.

Most of the pregnant women knew about HIV/AIDS through sources like the Media and the health facilities where they sought health care services.

Source: Data collected from Mukono Health Centre IV for this research project showed that 84(95.5\%) of the women who attended the health center claimed that they did not have any extramarital affairs while only $4(4.5 \%)$ asserted that they were involved in extramarital relationships respectively.

$87(98.9 \%)$ of all the pregnant women reported that they sought antenatal care services in the health facility free of charge compared to only one client $1.1 \%$ who claimed to have been charged at the health facility.

A very low number $34(38.6 \%)$ of the pregnant women who attended Mukono Health Centre IV had tested for HIVIAIDS as a couple.

Almost all of the pregnant women 87(98.9\%) who attended the facility for Antenatal health care reported that HIVIAIDS was still a big problem both socially and economically in contrast to only $1.1 \%$ who claimed otherwise.

The method of prevention for HIV/AIDS preferred by the respondents were recorded as follows; abstinence $3(3.4 \%)$ condom use $18(20.4 \%)$ while faithfulness accounted for $67(76.2 \%)$.

Finally, only 54(61.4\%) of the pregnant women reported that they were satisfied with the nature of antenatal care services that they received from the health facility.

$6(7 \%)$ of all the women who attended to the health centre were HIV positive while 82(93\%) where negative as shown in figure 2 above.

The majority of the respondents 54/88(61.4\%) reported that the commonest way through which HIV/AIDS is spread is through un protected sex with an infected partner, this was closely followed by MTCT which accounted for $22 / 88(25 \%)$ as shown in figure 3. 


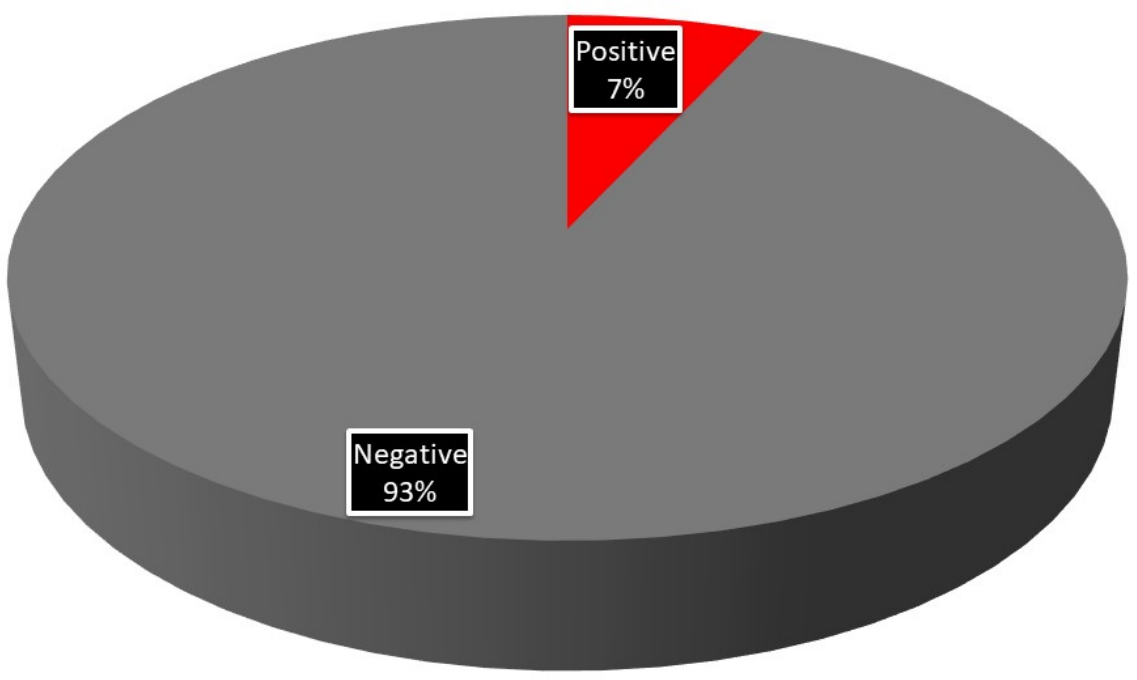

Figure 1. Prevalence of HIVIAIDS in pregnant mothers attending the ANC at Mukono Health Centre IV

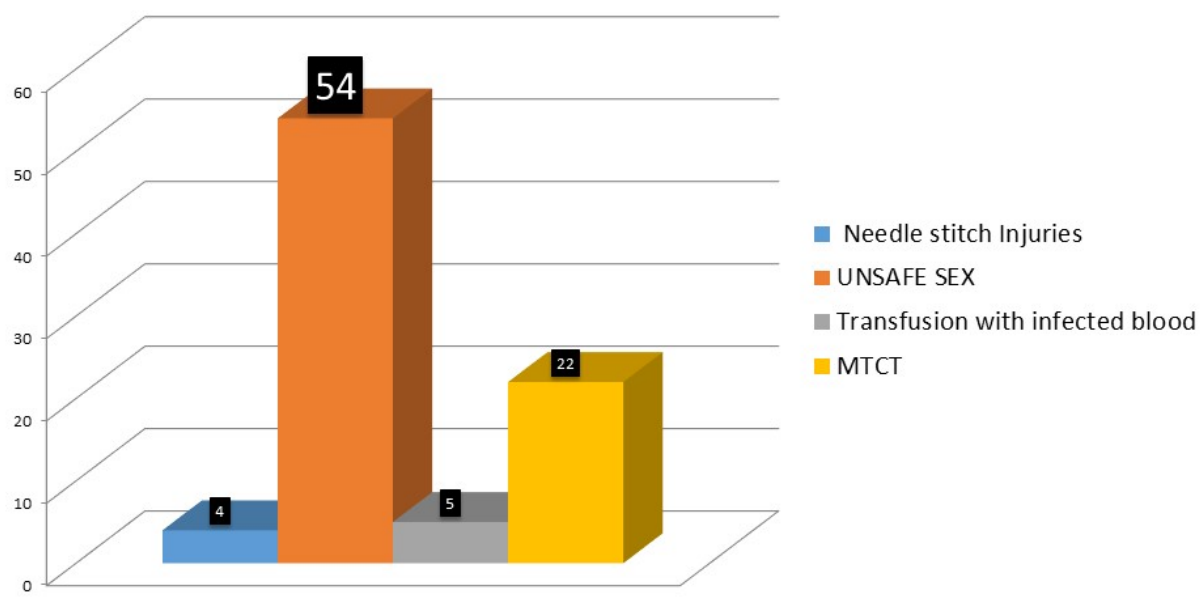

Figure 2. Ways through which HIVIAIDS is transmitted 
Table 1. Demographic characteristics of the respondents $(n=88)$

\begin{tabular}{|c|c|c|}
\hline & Frequency & Percentage (\%) \\
\hline \multicolumn{3}{|l|}{ Characteristics } \\
\hline \multicolumn{3}{|l|}{ Age } \\
\hline $18-24$ & 26 & 29.5 \\
\hline $25-31$ & 49 & 55.7 \\
\hline $32-38$ & 10 & 11.4 \\
\hline 39-45 and above & 03 & 3.4 \\
\hline \multicolumn{3}{|l|}{ Marital status } \\
\hline Single & 04 & 4.5 \\
\hline Married & 79 & 89.8 \\
\hline Widowed & 05 & 5.7 \\
\hline \multicolumn{3}{|l|}{ Level of Education } \\
\hline Primary & 25 & 28.4 \\
\hline Secondary & 31 & 35.2 \\
\hline Tertiary & 30 & 34.1 \\
\hline None & 02 & 2.3 \\
\hline \multicolumn{3}{|c|}{ Tribe of respondents } \\
\hline Baganda & 69 & 78.4 \\
\hline Basoga & 06 & 6.8 \\
\hline Banyankole & 03 & 3.4 \\
\hline Others & 10 & 11.4 \\
\hline \multicolumn{3}{|c|}{ Employment status } \\
\hline Employed & 39 & 44.3 \\
\hline Unemployed & 51 & 55.7 \\
\hline Religion & 30 & 34.1 \\
\hline Anglican, & 43 & 48.9 \\
\hline Catholic, & 11 & 12.5 \\
\hline Muslim, Adventist & 4 & 4.5 \\
\hline \multicolumn{3}{|l|}{ Area of residence } \\
\hline Urban & 41 & 6.6 \\
\hline Rural & 27 & 30.7 \\
\hline Semi urban & 20 & 22.7 \\
\hline
\end{tabular}

\section{DISCUSSIONS, CONCLUSIONS, AND RECOMMENDATIONS}

From the results of this study, the prevalence of HIV/AIDS in the Mukono H/CIV Mukono district was found to be at $7 \%$.

According to this study, Sexual transmission of HIV accounts for about $61 \%$. The major risk factors for the high prevalence of HIV/AIDS according to this study were reported to be having sex with an infected partner which was in support with findings from a study conducted by (Vithalani et al., 2018) which reported that the potential for sexual activity to transmit HIV/AIDS is more than a quarter were sexually active is with more than one partner.

The study identified the level of education, occupation, and age as being significantly associated with the level of knowledge on the general spread of HIV/AIDS. Only $38.6 \%$ of the pregnant women who attended Mukono Health Centre IV had information concerning HIV/AIDS tests by the spouse. Almost all of the pregnant women $98.9 \%$ who attended the facility for Antenatal health care reported that HIVIAIDS was still a big problem both socially and economically. These findings are supported by a study by Kayeyi, et al., (2019) that reported that educational attainment was found to be a strong determinant of HIV infection in both urban and rural population. This study also revealed that $7 \%$ of the HIV-positive pregnant women are more knowledgeable than HIV-negative women about variables like the use of ARV and PTMCT. This may be because being HIV positive raises concerns about one's health and that of the unborn 
Table 2. Factors affecting prevalence of HIV/AIDs in Mukono Health Centre IV

\begin{tabular}{|c|c|c|}
\hline & Frequency $(\mathrm{N}=88)$ & Percentage (\%) \\
\hline \multicolumn{3}{|l|}{ Variable } \\
\hline Extra marital relationship & 4 & 4.5 \\
\hline Yes & 84 & 95.5 \\
\hline \multicolumn{3}{|l|}{ No } \\
\hline Challenges in testing for & 2 & 2.3 \\
\hline HIVIAIDS & 1 & 1.1 \\
\hline Absence of kits. & 1 & 1.1 \\
\hline Inappropriate patient to health & 2 & 2.3 \\
\hline worker ratio. & 82 & 93.2 \\
\hline \multirow{2}{*}{\multicolumn{3}{|c|}{$\begin{array}{l}\text { Bad language by health worker. } \\
\text { All the above. }\end{array}$}} \\
\hline & & \\
\hline \multicolumn{3}{|l|}{ None of the above. } \\
\hline Payment of services & 1 & 1.1 \\
\hline Yes & 87 & 98.9 \\
\hline \multicolumn{3}{|l|}{ No } \\
\hline Tested for HIV with spouse & 34 & 38.6 \\
\hline Yes & 8 & 9.1 \\
\hline No & 46 & 52.3 \\
\hline \multicolumn{3}{|l|}{ I don't know } \\
\hline Is HIVIAIDS still a problem & 87 & 98.9 \\
\hline Yes & 1 & 1.1 \\
\hline \multicolumn{3}{|l|}{ No } \\
\hline Prevention of HIVIAIDS Absti- & 4 & 4.5 \\
\hline nence Faithfulness Condom use & 62 & 70.5 \\
\hline \multirow[t]{2}{*}{ EMTCT } & 18 & 20.5 \\
\hline & 4 & 4.5 \\
\hline Methods preferred by respon- & 3 & 3.4 \\
\hline dents Abstinence, Faithfulness, & 67 & 76.2 \\
\hline Condom use & 18 & 20.4 \\
\hline General comments on ANC Sat- & 54 & 61.4 \\
\hline \multirow[t]{2}{*}{ isfactory Average Unsatisfactory } & 33 & 37.5 \\
\hline & 1 & 1.1 \\
\hline \multicolumn{3}{|l|}{ Knowledge about HIVIAIDS } \\
\hline Yes & 87 & 98.9 \\
\hline No & 01 & 1.1 \\
\hline \multirow{2}{*}{\multicolumn{3}{|c|}{$\begin{array}{l}\text { Source of information about } \\
\text { HIVIAIDS }\end{array}$}} \\
\hline & & \\
\hline Media & 23 & 26.1 \\
\hline Health facility & 34 & 38.6 \\
\hline All the above & 31 & 35.2 \\
\hline
\end{tabular}


child. Also during counseling HIV positive pregnant women are given additional information on ARV prophylaxis, infant feeding issues, disclosure, and partner testing. The attitude a person has on something may affect the interest of that person knowing or utilizing it. Most of the pregnant women felt that it was important for pregnant women to be tested for HIV and a few did not see the importance of knowing. The reason for this may be the fear of being stigmatized by the community.

In this study, there was a slightly low level of testing for HIV/AIDS among couples for various reasons ranging from stigma to being divorced by the partners. Most of the women who attended the health facility were satisfied with the health care services that they were given. Finally, this study showed that there was a general prevalence of $7 \%$ of HIV/AIDS among the pregnant women who attended antenatal clinic at Mukono health center IV, these findings are in line with that that was obtained by NHSBS of 2004/05 estimated HIV prevalence among women at $7.5 \%$ relative to $5 \%$ among men. This pattern is more significant in urban areas and also among young women where for example the prevalence rate among the 15-19-year-olds was about 9 times higher among young women than young men. HIV prevalence was higher among urban residents at $10.2 \%$ compared to $5.7 \%$ among rural residents.

\section{Conclusions}

From this study, it was concluded that the general prevalence of HIVIAIDS among pregnant women who sought ANC in Mukono Health Centre IV was 7 $\%$.

\section{Recommendations}

More sensitive techniques like Elisa, DNA/PCR methods should be used to screen mothers who test negative due to window periods.

Positive mothers should get access to receive continuous psychological support hence enhancing the utilization of VCT by the mothers.

The antenatal laboratory should be supported with standard operating procedures on HIV screening (SOPs).

Men's involvement is necessary, and they need to be encouraged and sensitized from the communities to accompany their partners to the clinic and attend counseling sessions, this was help equip them both with the necessary information on PMTCT.
The government of Uganda should facilitate all local leaders from grassroots in villages to enforce laws that make it mandatory for every pregnant woman in their society to always seek antenatal care services in the nearest health facilities around them.

Furthermore, the government should provide incentives to pregnant women like the provision of free treated mosquito nets and free ART treatment and dietary supplements to all those who are tested positive to boost their immunity in preparation for childbirth.

The provision of FP services appears to be passive in HIV settings. In some VCT settings, clients receive information only if they ask for it. Provision of information and methods should be more proactive by providers, backed up by guidelines and protocols.

Policymakers should be sensitized to the desire among HIV-positive women and men for access to contraception to help them have the number of children they want.

\section{Acknowledgment}

I would like to thank Mr. Katumba James Davis, my supervisor who mentored and helped me during the time of proposal development up to this level of report writing my sponsors, the Baylor College of Medicine for the financial support that has enabled me to travel this far. Sincere appreciation goes to my mother Hamidah Nalumansi, my wife Namugaya Teddy, my children Nalumansi Hamidah, Abdurazak Kalenzi, and my entire family for the moral support offered during this period I have been at school.

Great thanks go the staff of Health Tutors' College Mulago, the lecturers from Makerere University College of Health Sciences and College of Education for their tireless efforts and support towards this academic achievement not forgetting my college mates for their guidance, the study participants for accepting to participate in the study and the research assistants for data collection. May the grace of God be with you all.

\section{ABBREVIATIONS}

AIDS: Acquired Immune Deficiency Syndrome

HIV: Human Immune Deficiency Virus

UDHS: Uganda Demographic and Health Survey 
UNAIDS: Joint United Nations Programme on HIV/AID

UBS: Uganda Beaural of Statistics

HSD: Health Sub District

HIS: HIV Indicator Survey

WHO: World Health Organisation

UNGASS: United Nations General Assembly Special Session

UNICEF: United Nations Children Fund

UHSBS: Uganda HIV Sero-Behavioral Survey

CD4: Cluster Differentiation

PMTCT: Prevention of Mother to Child Transmission of HIV

PEP: Post-exposure Prophylaxis

PCR: Polymerase Chain Reaction testing

VCT: Voluntary Counselling and Testing

RCT: Routine Counselling and Testing

PDF: Picture Document File

STDs: Sexually Transmitted Diseases

ALPHA: Analyzing Longitudinal Populationbased HIVIAIDS data from the network for Africa

UPEP: Uganda poverty reduction action plan

UAC: Uganda Aids Commission

JUNPA: Joint United Nations Programme on HIV/AIDS

\section{OPERATIONAL DEFINITIONS}

AIDS Acquired Immuno Deficiency Syndrome

Prevalence Number of cases (HIV) present expressed in percentage

Mortality Number of people dying in a given period of time

Post partum Means the life of the mother immediately after delivery

Antenatal As the period between the periods of conception to delivery

Opportunistic infection Are infections which come as a result of immune suppression

Meningitis Inflammation of the meninges

Research assistant Is one who employed to aid in research

Incidence Is the number of new cases of a condition.

\section{References:}

1). ALPHA, Hospitalier de Kigali. (2008) HIV infection on pregnancy-related mortality in sub-Saharan Africa: secondary analyses of pooled communitybased.
2). Barbra J., Howard .John F., Kaiser. (2004) clinical and pathogenic microbiology 2nd edition.

3). Bjorkman., H . (2002) HIV/AIDS and poverty reduction strategies UNDP bureau for development policy.

4). Campbell-Yesufu, O. T., \& Gandhi, R. T. (2011). Update on human immunodeficiency virus (HIV)-2 infection. Clinical infectious diseases : an official publication of the Infectious Diseases Society of America, 52(6), 780-787. https://doi.org/10.1093/ci d/ciq248

5). CDC. (2006). The Global HIV/AIDS Pandemic. August 11, 2006 / 55(31);841-844.https://www.cdc. gov/mmwr/preview/mmwrhtml/mm5531a1.htm

6). Cheesbrough Monica (2005) district laboratory practice in tropical counties part 2. https://doi. org/10.1017/CBO9780511581304

7). international Monetary fund ( 2000). Poverty Reduction Strategy Paper Uganda's Poverty Eradication Action Plan Summary and Main Objectives. Ministry of Finance, Planning and Economic Development. https://www.imf.org/external/NP/prsp/2 000/Uga/01/

8). Jawet., Melnick,A., (2007) Chapter 44., Lange Medical Microbiology.

9). Joint United Nations Progrmme on HIV/AIDS (2006)"overview of the global AIDS epidemic"Report on the global AIDS epidemic.

10). Kayeyi, N., Sandøy, I.F. \& Fylkesnes, K. Effects of neighbourhood-level educational attainment on HIV prevalence among young women in Zambia. BMC Public Health 9, 310 (2009). https://doi.org/10. 1186/1471-2458-9-310

11). Kiddugavu, M., (2003) hormonal contraceptive use and HIV 1 infection.

12). Mbirimtengerenji N. D. (2007). Is HIV/AIDS epidemic outcome of poverty in sub-saharan Africa?. Croatian medical journal, 48(5), 605-617.

13). Rice, B.D., Bätzing-Feigenbaum, J., Hosegood, V. (2007). Population and antenatal-based HIV prevalence estimates in a high contracepting female population in rural South Africa. BMC Public Health 7, 160. https://doi.org/10.1186/1471-2458-7 $-160$

14). Uganda bureau of statistics and ORC $\operatorname{marc}(2001)$.

15). UNAIDS \& WHO. (2005). AID epidemic update Special Report on HIV Prevention. https://data.unaids.org/publications/irc-pub 06/epi_update2005_en.pdf 
16). UNAIDS (2014). The HIV And AIDS Uganda Country Progress Report. https://www.unaids.org/ sites/default/files/country/documents/UGA_narra tive_report_2015.pdf

17). USAID, 2002 What happened in Uganda Declining HIV prevalence, behaviour change, and the national response; Washington,D.C.

18). Vithalani, J., \& Herreros-Villanueva, M. (2018). HIV Epidemiology in Uganda: survey based on age, gender, number of sexual partners and frequency of testing. African health sciences, 18(3), 523-530. https://doi.org/10.4314/ahs.v18i3.8 